\title{
The impact of human resource factors on lightning safety performance
}

\begin{abstract}
There have been studies in the area of safety guidelines and safety performance in organizational level, but scarce research still exists regarding to the lightning safety performance and its antecedents. This study has identified organizational factors in the area of human resources consist of communication and feedback, incentives and rewards which assume that help to improve lightning safety performance, and examined the degree to which they have contributed to lightning safety performance in Iranian companies. Results confirmed that the factors of communication and feedback, incentives and rewards are positively contributed to lightning safety performance in Iranian manufacturing companies.
\end{abstract}

Keyword: Human resource factors; Communication and feedback; Incentive and rewards; Lightning safety performance 